\title{
Avances en la investigación en torno a la relación entre migración y fecundidad: cambios y perspectivas, $1970-2016$
}

\author{
Ricardo Regules García*
}

Recepción: 5 de abril de 2017 Aceptación: 21 de junio de 2017

Resumen La pregunta central que guía esta revisión de literatura es ¿cómo se ha abordado en la investigación sociodemográfica la relación entre migración y fecundidad? En este trabajo, además de discutir algunos de los hallazgos en torno a ella, se hace un recuento de los niveles de análisis enfatizados, las fuentes de información utilizadas y los cambios ocurridos en la medición del fenómeno en el periodo 1970-2016. También se discuten los alcances y las limitaciones de las perspectivas teóricas a partir de las cuales se han explicado los niveles y las tendencias de la fecundidad de la población migrante, tanto en los lugares de origen como en los de destino. Con base en lo anterior, también se identifican rutas para investigaciones futuras que contribuyan a mejorar nuestra comprensión del comportamiento reproductivo de las personas migrantes.

PALABRAS CLAVE: estado del arte, revisión de la literatura, migración interna, migración internacional, fecundidad, preferencias de fecundidad.

Abstract The following question is central to this literature review: how has the relationship between migration and fertility been addressed in sociodemographic research? In addition to discussing some of the most relevant findings on the topic of migration and fertility, this work presents an exhaustive account of the levels of analysis, the information sources and databases, and the changes in measuring the phenomenon in the period from 1970 to 2016. This work also discusses the scopes and limitations of a number of hypotheses than have been proposed to explain the mechanisms through which migration may impact fertility behavior in places of origin and destination. Based on the aforementioned, suggestions for further research are outlined in order to improve our understanding of migrants' fertility behavior.

KEY WORDS: state of the art, literature review, internal migration, international migration, fertility, fertility preferences.

Becario del Programa de Becas Posdoctorales de la Universidad Nacional Autónoma de México (UNAM), Programa Universitario de Estudios del Desarrollo, regulesg@gmail.com 


\section{Introducción}

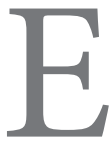

n este trabajo se revisa la literatura sobre la relación entre migración y fecundidad con el propósito de sintetizar las perspectivas y los conocimientos acumulados a través del tiempo, pero también de indicar algunas rutas para la investigación futura. La forma en que se estructuró la revisión de las investigaciones sobre el tema indica su evolución teórica; se perfilan las hipótesis que explican la fecundidad de las personas migrantes tanto en los lugares de destino como en los de origen, los niveles de análisis enfatizados, los cambios ocurridos en la medición del fenómeno y la evidencia de cómo diversos marcos conceptuales incorporan o descartan factores específicos con base en los diferentes intereses por estudiar la dinámica entre la fecundidad y la migración interna e internacional.

Si bien las primeras investigaciones sobre la relación entre migración y fecundidad datan de mediados de la década de los treinta del siglo pasado (Dorn \& Lorimer, 1936; Kiser, 1938), adquieren relevancia a inicios de los setenta, ${ }^{1}$ cuando comienzan a perfilarse algunas de las primeras hipótesis que explican la fecundidad no solo de los migrantes internos sino también de los internacionales. Con la finalidad de ofrecer una visión lo más completa posible de la gran diversidad de esfuerzos por sistematizar y operacionalizar las hipótesis analíticas y explicativas de la fecundidad de los migrantes, se hizo una revisión del conocimiento acumulado entre los años 1970 y 2016, que incluyó 38 trabajos publicados en revistas indexadas vinculadas a los estudios de población y demografía. Con respecto a la cobertura geográfica en esta revisión de literatura, las investigaciones son diversas pues refieren a México, Estados Unidos y Canadá, pero también a Australia y países de Europa, Asia, África y la región latinoamericana.

Para mostrar la evolución cronológica de las teorías y las herramientas de análisis, según la discusión de las diferencias respecto a las aproximaciones teóricas, en esta revisión de literatura fueron separadas las investigaciones sobre migración interna y fecundidad (18 trabajos) de las que analizan la asociación de esta con la migración internacional (20 trabajos). Es importante aclarar que la revisión de la literatura sobre la relación entre migración internacional y fecundidad marital refiere únicamente a inmigrantes de primera generación, es decir, a personas que se desplazan de un país para asentarse en otro.

En las últimas secciones se reflexiona sobre los aspectos teórico-metodológicos de la investigación, pero también acerca de los presupuestos en los que se fundamen-

1

Macisco, Bouvier y Renzi (1969) enumeran investigaciones sobre migración y fecundidad publicadas entre 1936 y 1968. En su mayoría, estos trabajos refieren a la relación entre migración interna y fecundidad. 
tan las hipótesis más utilizadas para explicar la fecundidad de los migrantes. A partir de lo anterior, y con el fin de problematizar la interrelación entre migración y fecundidad, se plantea la necesidad de considerar el análisis de otras dimensiones de la dinámica familiar (matrimonios mixtos), el comportamiento reproductivo (preferencias de fecundidad) y el papel de la migración en el sistema global de la reproducción demográfica (Canales, 2015), pero también de incorporar marcos analíticos que han sido desarrollados desde la perspectiva de otras disciplinas, y aproximaciones metodológicas cualitativas o mixtas.

Con respecto a la migración internacional, conviene mencionar la existencia de publicaciones que analizan los patrones y las tendencias de la fecundidad de la población migrante de segunda y tercera generación, es decir, hijos o nietos de inmigrantes nacidos en el lugar de destino (Amaro, 1988; Stephen \& Bean, 1992; Perlmann \& Waldinger, 1997; Frank \& Heuveline, 2005; Parrado \& Morgan, 2008; Milewsky, 2011; Parrado, 2011). Si bien estas investigaciones no se discuten en la presente revisión de la literatura, algunas se retoman en las últimas secciones a fin de enriquecer la discusión en torno no solo a los métodos para estimar la fecundidad de los migrantes sino también a sus implicaciones para la política pública, económica y migratoria en los países de destino.

Perspectivas teóricas para explicar la fecundidad de los migrantes: hipótesis y procesos

La evidencia empírica de la investigación indica una asociación entre fecundidad y migración. Los hallazgos se han interpretado en términos de los procesos de socialización, selectividad, ruptura o separación, adaptación y asimilación o aculturación, los cuales se describen a continuación con el propósito de familiarizar al lector con las hipótesis que comúnmente se utilizan para explicar la fecundidad de la población migrante y de facilitar la lectura de las siguientes secciones.

La hipótesis de socialización arguye que los niveles y las tendencias de fecundidad de la población migrante observados en los lugares de destino son producto de preferencias adquiridas durante la infancia y juventud por medio del proceso de socialización temprana con los padres y otros miembros de la familia (Hervitz, 1985; Juárez, 1996; Castro Martín \& Roseo-Bixby, 2011). Además de resaltar el poder condicionante de las normas de fecundidad que prevalecen en los lugares de origen, la hipótesis sostiene que estas preferencias se pueden reforzar mediante los lazos que los y las migrantes mantienen con su región de origen (Castro Martín \& RoseoBixby, 2011). 
Por otro lado, el proceso de selectividad migratoria comprende atributos demográficos y socioeconómicos —edad, escolaridad, situación conyugal, lugar de residencia, etc. - que distinguen a la población emigrante de la no migrante en el lugar de origen; argumenta que los patrones y las tendencias de la fecundidad resultan de preferencias reproductivas particulares de la población que emigra. La hipótesis de selectividad presupone que las preferencias de fecundidad se definen durante el proceso de socialización temprana, pero también sostiene que este proceso presenta distintos matices, según el lugar de origen o de residencia. Además de las diferencias entre las preferencias de fecundidad de la población emigrante y las de la población no migrante en los lugares de origen, existen diferencias entre las preferencias de los migrantes que provienen de regiones rurales y las de quienes proceden de áreas más urbanizadas.

En cuanto a las hipótesis que explican por qué la migración tiene efectos que reducen o estimulan la fecundidad, el proceso de ruptura o separación se refiere a la consecuencia de la migración per se. En los lugares de origen, la ruptura o separación temporal del núcleo conyugal reduce los niveles de fecundidad durante el período que sigue a la emigración puesto que disminuye la frecuencia de las relaciones sexuales entre la pareja y, por tanto, la exposición al riesgo de embarazo (Massey \& Mullan, 1984; Hervitz, 1985; Menken, 1979; Bongaarts \& Potter, 1979; Lindstrom \& Giorguli, 2002, 2007; Milewski, 2007). Sin embargo, se espera que la reducción en la fecundidad sea temporal y regrese a su nivel original una vez que los migrantes retornan a los lugares de origen y compensan el tiempo de reproducción perdido (Hervitz, 1985). Tanto Menken (1979) como Bongaarts y Potter (1979) desarrollaron modelos matemáticos de simulación que mostraron los efectos de la separación temporal del núcleo conyugal a causa de la migración sobre la fecundidad, específicamente un efecto reductor en las probabilidades de ocurrencia de los nacimientos: por ejemplo, Menken (1979) estimó que ocho meses de separación reducían la probabilidad de que ocurriera un nacimiento entre $33 \%$ y un $46 \%$.

La hipótesis de adaptación explica los niveles de fecundidad de los núcleos conyugales migrantes en los países de destino. Atribuye los cambios en la fecundidad a las oportunidades y dificultades socioeconómicas que enfrentan los migrantes en el país receptor, como mayores oportunidades laborales, sobre todo para la mujer, pero también alzas en el costo de la vida (Castro Martín \& Rosero-Bixby, 2011). Esta hipótesis sostiene que el núcleo conyugal reduce temporalmente su fecundidad para maximizar los beneficios y minimizar los costos de la migración (Hervitz, 1985; Lindstrom \& Giorguli, 2002).

Otra hipótesis que se ha utilizado para explicar la relación entre migración y fecundidad es la asimilación o aculturación. Estos procesos comprenden la atemperación gradual de los individuos al pasar de una cultura a otra con la cual tienen 
contacto directo y continuo. La asimilación y aculturación consisten en incorporar elementos socioculturales y, por tanto, reajustar los patrones culturales individuales. En términos de comportamiento reproductivo, la hipótesis de asimilación o aculturación establece que a medida que se asimilan, los inmigrantes van adoptando las normas y preferencias de fecundidad de la sociedad receptora. En su forma más refinada, esta hipótesis reconoce que tanto el efecto de adaptación como el de exposición al contexto normativo y cultural del país de destino sobre el comportamiento reproductivo dependen de la edad y la fase del ciclo familiar en que ocurre el evento migratorio (Weller \& Macisco, 1971; Toulemon \& Mazuy, 2004; Castro Martín \& Roseo-Bixby, 2011).

Además de las hipótesis de socialización, selectividad, ruptura o separación, adaptación y asimilación o aculturación, se han propuesto explicaciones alternativas para la fecundidad de los y las migrantes. Una de ellas es la hipótesis de la interrelación de eventos, que resalta la interconexión de acontecimientos demográficos y sociales como la migración, la reunificación y la formación de una familia. Por ejemplo, los elevados valores de la fecundidad que registran algunas subpoblaciones de inmigrantes al poco tiempo de su arribo al país receptor podrían ser consecuencia de la compensación por el tiempo de reproducción perdido. Este último resulta de la separación temporal del núcleo conyugal o del aplazamiento deliberado de embarazos en respuesta a la emigración (Toulemon, 2004; Milewski, 2007).

Finalmente, la hipótesis de legitimación arguye que la fecundidad de los inmigrantes, específicamente de aquellos que no pueden acreditar su estancia legal en los países de destino, depende de la revaloración de los hijos como posibles iniciadores de vínculos y precursores de derechos y beneficios jurídicos en los países de destino (Bledsoe, 2004). Sin embargo, los altos niveles de fecundidad podrían ser el resultado de una demanda insatisfecha de métodos de anticoncepción, precisamente porque su estatus migratorio, por lo regular de "indocumentados" en el país receptor, condiciona y limita el acceso a la planificación familiar y a los programas de salud reproductiva.

\section{Los estudios sobre migración interna y fecundidad}

Los objetivos de esta sección son los siguientes: primero, describir cómo ha sido relacionada la migración interna con los niveles de fecundidad; segundo, dilucidar cómo se comparan las poblaciones migrantes y no migrantes con respecto a su comportamiento de fecundidad teniendo en cuenta las hipótesis de socialización, selectividad, ruptura o separación, adaptación y asimilación; tercero, examinar las 
diferentes maneras de operacionalizar las hipótesis que explican la fecundidad de los migrantes internos, y cuarto, discutir sus limitaciones teórico-metodológicas.

Como se mencionó en la introducción, las investigaciones sobre la relación entre la migración y la fecundidad comenzaron en la década de 1930. Sin embargo, Macisco et al. (1970) fueron de los primeros en argumentar que la reducción en los niveles de fecundidad marital de la población migrante podía ser resultado no solo de un proceso de selectividad sino también de un proceso de adaptación a las condiciones socioeconómicas y a las oportunidades laborales en el lugar de destino. Estos autores analizaron las diferencias en las tendencias de fecundidad entre la población migrante rural-urbana y la población no migrante en la ciudad de San Juan, Puerto Rico. Consideraron los efectos de la edad y de la participación de la mujer en las actividades laborales, describieron los niveles de fecundidad marital y encontraron que eran más bajos en el grupo de varones inmigrantes cuyas esposas realizaban actividades remuneradas que en el grupo de varones inmigrantes casados o unidos con mujeres que no formaban parte de la fuerza laboral y que los de la población no migrante en dicha ciudad. Según estos autores, tales diferencias podían ser consecuencia de un proceso de selección que favorecía la emigración de quienes tuvieran mayores aspiraciones de movilidad social ascendente $y$, por tanto, buscasen mejores oportunidades económicas en la ciudad. Cabe señalar que los autores utilizaron información censal para analizar la relación entre migración interna y fecundidad, método transversal de recolección de datos sociodemográficos que presentó serias limitaciones para la investigación; primero, porque la información sobre la migración interna se refería solo a los cinco años previos al levantamiento del censo, y segundo, porque los datos del censo sobre la fecundidad concernían únicamente al número total de hijos que tenían las mujeres. En consecuencia, los autores no pudieron determinar si los nacimientos ocurrieron antes o después del evento migratorio o bien antes o después de la integración de las mujeres en la fuerza laboral.

Goldstein (1973) también utilizó datos censales para analizar la relación entre migración interna y fecundidad en Tailandia. A diferencia de Macisco et al. (1970), quienes categorizaron al subconjunto de mujeres en migrantes y no migrantes y utilizaron como referencia el estatus migratorio de sus cónyuges o parejas, Goldstein (1973) subdividió la muestra de la población de mujeres en tres categorías analíticas, según su experiencia migratoria: mujeres no migrantes; mujeres migrantes permanentes (es decir, las que al momento del levantamiento censal residían en una provincia distinta de la provincia en la que nacieron), y mujeres que cinco años antes del censo residían en una provincia distinta de aquella en donde vivían cuando se les entrevistó. Entre los hallazgos de su estudio resalta que, aun después de controlar por el efecto de los grupos etarios, el número promedio de hijos nacidos vivos del grupo 
de mujeres migrantes permanentes era parecido al de la población de mujeres no migrantes en la capital del país y en otros centros urbanos. Según Goldstein (1973), esta tendencia podía resultar de la asimilación paulatina de las normas y preferencias de fecundidad que prevalecían en la sociedad receptora. Por otro lado, el promedio de hijos nacidos vivos de las mujeres migrantes permanentes y de las mujeres que cinco años antes residían en otra provincia se mantuvo por debajo del de la población no migrante en las localidades rurales. Goldstein (1973) argumentó que en estos casos los hallazgos podían estar vinculados con el proceso de selectividad, que favorecía la emigración de mujeres con preferencias por familias de menor tamaño. Sin embargo, la falta de datos retrospectivos sobre migración y fecundidad impidió profundizar en el análisis de la interrelación que ambos fenómenos demográficos guardan entre sí y, por tanto, determinar con más precisión si los niveles de fecundidad observados en las distintas categorías migratorias resultan de un proceso de selección o de otros procesos, por ejemplo el de adaptación y el de asimilación.

En otro intento por esclarecer la relación entre migración interna y fecundidad en Tailandia, Goldstein y Goldstein (1981) dispusieron de información censal y utilizaron el método de los hijos propios ${ }^{2}$ como una herramienta que coadyuvara a visualizar los efectos de la selectividad y de la ruptura o separación sobre la fecundidad. Dividieron a la subpoblación de mujeres casadas de entre 20 y 49 años de edad en dos grupos: mujeres con "hijos propios" de menos de un año de edad y mujeres con "hijos propios" de entre uno y cuatro años. Esto con base en dos presupuestos: primero, que casi todas las mujeres con hijos de menos de un año de edad dieron a luz después de emigrar, y segundo, que la mayoría de los nacimientos que experimentaron las mujeres con hijos de entre uno y cuatro años ocurrieron antes del evento migratorio. Con fines comparativos, los autores categorizaron a las mujeres en migrantes y no migrantes, pero también por lugar de residencia al momento del censo. Desarrollaron dos modelos multivariados para medir la intensidad de la asociación entre la condición migratoria de las mujeres y la probabilidad de tener "hijos propios" de menos de un año de edad e "hijos propios" de entre uno y cuatro años. En los modelos, Goldstein y Goldstein (1981) controlaron por la edad e incluyeron variables socioeconómicas tales como el lugar de residencia al momento

2 El método de los hijos propios parte de la base de que los niños menores de un año de edad que registra el censo son los sobrevivientes de los nacimientos ocurridos en el año anterior al mismo; los niños de un año de edad corresponden a los nacimientos en el segundo año anterior al censo y así sucesivamente. Si se logra identificar a la madre de los niños, será posible estimar los nacimientos por edad de ella para cada uno de los años anteriores al censo. Esta proyección retrospectiva se realiza utilizando un conjunto adecuado de relaciones de sobrevivencia. De modo similar, y a partir de las mujeres registradas en el censo, se estima la población femenina por edad en cada periodo anual anterior al censo. De esta forma se obtienen estimaciones de las tasas de fecundidad por edad en los años que preceden al censo (CELADE, 1981). 
del censo, la condición laboral y la escolaridad. De los resultados de los modelos, destacó que las mujeres no migrantes tenían mayores probabilidades de tener "hijos propios" de entre uno y cuatro años que las mujeres migrantes. Sostuvieron que los hallazgos de los modelos podían atribuirse a la selectividad migratoria o a la compensación por el tiempo de reproducción perdido que resulta de la disrupción de la fecundidad cuando los individuos emigran.

El tipo de localidad de donde provienen los migrantes es una variable fundamental para explicar su fecundidad puesto que está vinculada al proceso de socialización y, por tanto, al comportamiento reproductivo futuro (Bach, 1981; Juárez, 1996). Sin embargo, las características del lugar de destino también pueden tener efectos en la fecundidad a través de los procesos de adaptación y de asimilación o aculturación. A partir de este argumento, Bach (1981) evaluó la relación entre migración y fecundidad en Malasia con información de una encuesta familiar aplicada a mujeres casadas de entre 15 y 45 años de edad. El autor agrupó a la población de mujeres en nueve categorías, según su lugar de residencia antes y después de contraer matrimonio. ${ }^{3}$ Posteriormente estimó el número promedio de hijos nacidos vivos para cada categoría y comparó los resultados entre sí. Encontró que el grupo de mujeres que antes de casarse residían en localidades rurales pero después de contraer nupcias emigraron a las ciudades (rural-ciudad), tenía en promedio menos hijos nacidos vivos que el grupo de mujeres no migrantes en las localidades rurales. No obstante, las mujeres que emigraron de las áreas rurales a las ciudades (rural-ciudad) tenían en promedio más hijos que las no migrantes en las ciudades. La categorización analítica que propuso Bach (1981) vinculó la migración con otra variable asociada a la fecundidad: el matrimonio. Dos presupuestos subyacen a esta categorización: primero, que los nacimientos ocurren después del matrimonio, y segundo, que la emigración los antecede. Sin embargo, debido a que la medida de la fecundidad refería al total de los hijos nacidos vivos, existía la posibilidad de que uno o más nacimientos hubieran ocurrido después del matrimonio, pero antes del evento migratorio. En forma sucesiva al análisis descriptivo, Bach (1981) utilizó un modelo estadístico que mostró que provenir de ciudades o pueblos reducía la probabilidad de las mujeres de tener más hijos, mientras que se incrementaba si provenían de localidades rurales. En cuanto a los lugares de destino, emigrar a las grandes ciudades también reducía la probabilidad de que las mujeres tuvieran más hijos. Según el autor, estos resultados reflejaban el papel preponderante de la emigraron a pueblos (ciudad-pueblo); mujeres que antes de casarse residían en ciudades, pero que después de contraer matrimonio emigraron a localidades rurales (ciudad-rural), y mujeres que antes y después de casarse residían en localidades rurales (no migrante rural). 
socialización temprana en la definición de la fecundidad, pero también la posibilidad de adaptación a los patrones reproductivos que prevalecían en las áreas urbanas y metropolitanas de Malasia.

Por su parte, Goldstein y Goldstein (1983) hicieron uso de otra encuesta familiar malaya no solo para identificar los efectos de los procesos de selectividad y de adaptación sobre la fecundidad sino también para evaluar si la migración per se tenía un efecto disruptivo en la fecundidad. A diferencia de las investigaciones discutidas antes (Macisco et al., 1970; Goldstein, 1973; Bach, 1981; Goldstein y Goldstein, 1981), en este trabajo se operacionalizó el concepto de adaptación a partir de la información sobre la experiencia migratoria acumulada en años. La paridad antes de emigrar, junto con otras características demográficas y socioeconómicas, fueron variables utilizadas para dar cuenta de los efectos del proceso de selectividad, mientras que el tipo de migración (rural-urbana, urbana-rural, urbana-urbana, rural-rural) continuó utilizándose como una variable aproximada a la socialización. En los resultados de la investigación destacó que en comparación con las mujeres que tenían más hijos, aquellas con menos descendencia presentaban mayores probabilidades de emigrar, lo cual se interpretó como un efecto de selección. Sin embargo, los autores también argumentaron que las mujeres con menos hijos podrían haber retrasado el calendario de su fecundidad de manera deliberada, puesto que los nacimientos se contraponían a su intención de emigrar. En este caso, la migración era un evento disruptivo del tempo de la fecundidad. Al final, Goldstein y Goldstein (1983) observaron una reducción en los niveles de fecundidad en los años que seguían a la inmigración, lo cual interpretaron en términos del proceso de adaptación.

Farber y Lee (1984) propusieron una manera alternativa para determinar si los migrantes rural-urbanos adaptaban su fecundidad a la fecundidad en los lugares de destino. El modelo propuesto comparó la fecundidad acumulada de un grupo de mujeres casadas que en 1969 había emigrado con la de un grupo de mujeres con características sociodemográficas similares que en 1969 aún no lo hacía, pero que lo hizo entre 1969 y 1974. La hipótesis inicial de los autores era que si las mujeres del primer grupo no hubieran emigrado, en 1969 tendrían niveles de fecundidad parecidos a los de las mujeres en el segundo grupo. Sin embargo, no sucedió así y los diferenciales de fecundidad entre los dos grupos resultaron estadísticamente significativos, con lo cual se concluyó que con el tiempo las mujeres migrantes adaptaban su fecundidad a las normas vigentes en las ciudades de destino.

Hasta aquí la revisión de la literatura sobre migración interna y fecundidad, y con base en la evidencia empírica, se puede concluir que las mujeres que emigraban del campo a las ciudades presentaban niveles de fecundidad que se encontraban por debajo de los que presentaban las mujeres no migrantes en los lugares de origen. Sin 
embargo, en estos trabajos no queda claro si la tendencia resultaba del proceso de adaptación o si solo reflejaba el hecho de que quienes emigran por lo regular poseen atributos demográficos y socioeconómicos específicos, tienen menos hijos y prefieren descendencias de menor tamaño, es decir, que se trata de individuos seleccionados (Lee \& Farber, 1985).

Con la intención de contribuir al esclarecimiento de las diferencias entre los efectos de la selectividad y de la adaptación sobre la fecundidad, Lee y Farber (1985) dieron continuidad a su investigación sobre la relación entre la migración ruralurbana y la fecundidad en Corea del Sur. Como Farber y Lee (1984), presupusieron que el número de hijos nacidos vivos en un periodo dado dependía del número de hijos nacidos vivos en el periodo $t-5$. Dicho de otro modo, si la fecundidad registrada cinco años antes al tiempo $t$ tanto para la población migrante rural-urbana como para la población rural no migrante era la misma, entonces la fecundidad en el tiempo t era una función de la edad, la edad al cuadrado y el estatus migratorio. En consecuencia, la diferencia en el número de hijos nacidos vivos entre la población migrante y la no migrante en los lugares de origen podía atribuirse al proceso de adaptación. En cuanto a los resultados de su modelo, observaron que, con respecto a los niveles de fecundidad de las mujeres en el lugar de origen, los niveles de fecundidad de las migrantes rural-urbanas se reducían considerablemente en cada uno de los cinco años que sucedieron a la migración. Además notaron que entre más grande era la ciudad de destino, la diferencia entre la fecundidad acumulada de la población migrante rural-urbana y la de la población no migrante en el origen se incrementaba. Lee y Farber (1985) interpretaron estos resultados como evidencia del proceso de adaptación.

Para Camerún, Lee (1992) recurrió al mismo modelo autorregresivo que Farber y Lee (1984) y Lee y Farber (1985) utilizaron en sus investigaciones. Sin embargo, en lugar de modelar el efecto de la migración rural-urbana sobre el número de hijos nacidos vivos, Lee (1992) utilizó como variable dependiente las tasas de fecundidad. A diferencia de lo que sucedía en Corea del Sur, en Camerún la diferencia entre las tasas de fecundidad de la población de mujeres migrantes rural-urbanas y las de la población de mujeres no migrantes en los lugares de origen fueron mínimas y carecieron de significancia estadística. Con base en estos resultados, Lee (1992) concluyó que el proceso de adaptación no operaba en el caso de Camerún, por lo menos no a finales de la década de los setenta, cuando se levantó la encuesta de la que provinieron los insumos para realizar su investigación. Posteriormente, Lee y Pol (1993) recurrieron al mismo modelo autorregresivo para hacer un estudio comparativo sobre la influencia de la migración rural-urbana en la fecundidad de los migrantes en Corea del Sur, Camerún y México. Para Corea del Sur y México, los resultados del modelo mostraron que las mujeres migrantes adaptaban sus niveles de fecundi- 
dad a los que prevalecían en las ciudades de destino, mientras que en el caso de Camerún los diferenciales de fecundidad entre los migrantes rural-urbanos y la población no migrante en el origen no fueron significativos. A diferencia de Corea del Sur y México, en Camerún el acortamiento en los tiempos de abstinencia postparto y de lactancia, la disminución de los matrimonios polígamos y el aumento de los matrimonios monógamos entre los migrantes internos eran factores que podían explicar los resultados.

Por otro lado, White, Moreno y Guo (1995) se centraron en analizar si la migración per se era un evento demográfico que interfería con la fecundidad de las mujeres migrantes en Perú. Modelaron los riesgos relativos de alcanzar un nacimiento y controlaron por los efectos de la edad, la edad a la primera unión, la paridad, el lugar de residencia al momento de la encuesta y la escolaridad. En el modelo de riesgo incluyeron la variable dicotómica "movimiento" para indicar si la mujer había emigrado entre 1981 y 1986. Aunque esta variable no resultó estadísticamente significativa, los autores concluyeron que el signo negativo del coeficiente indicaba un posible efecto reductor en el riesgo relativo de alcanzar un nacimiento. En cuanto a la selectividad, White et al. (1995) estimaron sus efectos de manera indirecta, a través del análisis de las variables asociadas con las probabilidades de las mujeres de emigrar. Los resultados del modelo de regresión logística indicaron que las mujeres que vivían en áreas rurales y con menos hijos nacidos vivos eran quienes presentaban mayores probabilidades de emigrar, lo cual sugería la presencia de un proceso de selección migratoria con respecto a la fecundidad entre las mujeres migrantes.

En Europa, Kulu $(2003,2006)$ analizó los efectos de la migración interna en los riesgos relativos de alcanzar el primero, segundo y tercer embarazo para las mujeres migrantes en Estonia (2003), y en Polonia y Austria (2006). La estrategia metodológica que utilizó en ambas investigaciones se diseñó para probar no solo si la fecundidad de los migrantes internos podía explicarse a partir de las hipótesis de selectividad y de adaptación sino también para identificar si la migración interfería con los riesgos relativos de alcanzar nacimientos. En ambos estudios controló por los efectos de la selectividad, al incluir en los modelos estadísticos variables demográficas y socioeconómicas, pero agregó un componente de heterogeneidad que diera cuenta de las características no observables de la selectividad. Para analizar el efecto de adaptación, Kulu $(2003,2006)$ construyó una variable categórica con base en el estatus de residencia (no migrantes en áreas rurales, migrantes en áreas rurales, no migrantes en pequeños pueblos, migrantes en pequeños pueblos, no migrantes en ciudades y migrantes en ciudades). Además, cuando modeló el riesgo relativo de alcanzar el tercer embarazo, el autor incluyó el "lugar de residencia del migrante cuando tenía catorce años" como variable aproximada al proceso de socialización 
temprana de la mujer, el cual está vinculado con su conducta y sus valores reproductivos futuros (Rodríguez \& Hobcraft, 1980). Para el caso de Estonia, Kulu (2003) encontró que las probabilidades de alcanzar un nacimiento subsecuente disminuían a medida que aumentaba el tamaño del lugar de residencia. Sin embargo, la disminución en las probabilidades era mucho más evidente en los nacimientos de orden mayor, lo cual podía resultar de la adaptación. Por otro lado, las mujeres migrantes internas presentaron niveles de fecundidad similares a los de la población no migrante en el destino, pero menores que los de la población no migrante en el origen. Si bien el resultado se atribuyó a los efectos de adaptación, Kulu (2003) reconoció que la selectividad migratoria podía contribuir en parte a la explicación de esta tendencia. Con respecto a los migrantes internos en Polonia y Austria (Kulu, 2006), los hallazgos fueron similares a los que observó para Estonia (Kulu, 2003). Sin embargo, las probabilidades de alcanzar el primer nacimiento fueron mayores en mujeres que emigraron por motivos ligados a la formación familiar.

Para el caso de Filipinas, Jensen y Ahlburg (2004) modelaron el riesgo relativo de alcanzar nacimientos subsecuentes después de emigrar. Tomaron en consideración el tipo de migración, es decir, si las mujeres emigraban de lugares menos a más urbanizados, de lugares más a menos urbanizados o bien hacia un lugar similar al de origen con respecto al tamaño y grado de urbanización. Estos autores supusieron que entre más urbanizado era el lugar de destino, menor era el nivel de fecundidad, por tanto las mujeres migrantes que tuvieran preferencias por descendencias de menor tamaño emigrarían hacia estos lugares, con lo cual se cumpliría la hipótesis de selectividad. Otra variable que se incluyó en el modelo fue si las mujeres se integraban en la fuerza laboral durante el periodo inmediato a la emigración. Según ellos, esta variable reflejaba los costos de oportunidad en los lugares de destino y podía utilizarse como un indicador del proceso de adaptación. Entre los hallazgos de esta investigación destaca que el riesgo relativo de alcanzar nacimientos subsecuentes era mucho menor para las mujeres migrantes que se incorporaban a la fuerza laboral después de inmigrar que para las mujeres migrantes que no realizaban actividades remuneradas en los lugares de destino. Los autores tomaron este resultado como evidencia de un proceso de adaptación a los costos de oportunidad en el lugar de destino. Por el contrario, los resultados del modelo no fueron concluyentes respecto a los efectos de la selectividad.

Chattopadhyay, White y Depbuur (2006) evaluaron los efectos disruptivos de la migración per se, la selectividad y adaptación en la fecundidad de las mujeres migrantes. Para controlar por los efectos de la selectividad, los autores incluyeron en su modelo estadístico variables demográficas y socioeconómicas, pero también otras que habían sido asociadas previamente a la migración en Ghana; por ejemplo, el tipo de religión. Para medir si la adaptación interfería con la fecundidad de las 
mujeres migrantes, estos autores incorporaron al modelo dos variables: la primera refería al tiempo de residencia en el lugar de destino, la segunda categorizaba a las mujeres según el tipo de migración (migrante rural-rural, urbana-urbana, ruralurbana, urbana-rural y no migrante). En cambio, el efecto disruptivo de la migración en la fecundidad se analizó a través del riesgo relativo de concebir durante el mismo año en cual ocurrió el evento migratorio. Los autores encontraron que las mujeres que migraban del campo a las ciudades tenían en promedio menos hijos nacidos vivos que las no migrantes en las localidades de origen. Según los autores, este resultado podía asociarse al proceso de selección migratoria, pero también al fenómeno de adaptación. Con respecto a este último, la única evidencia definitiva se observó entre las mujeres que emigraban de ciudades a localidades rurales. Por otro lado, el efecto disruptivo de la migración en los riesgos relativos de concebir no tuvo significancia estadística.

Por su parte, Gyimah (2006) investigó si las mujeres migrantes internas adaptaban su fecundidad a los niveles de fecundidad de los lugares de destino. Al igual que Chattopadhyay et al. (2006), utilizó la variable "tipo de migrante" para medir el efecto de adaptación en la fecundidad acumulada; sin embargo, añadió cuatro categorías: migrante rural-urbano reciente, migrante rural-urbano de largo plazo, migrante urbano-rural reciente y migrante urbano-rural de largo plazo. Con base en los resultados del modelo, Gyimah (2006) llegó a conclusiones similares a las de Chattopadhyay et al. (2006). No obstante, observó que con respecto a los migrantes recientes, los de largo plazo tendían a adaptar su fecundidad a los niveles que prevalecían en los lugares de destino.

En cuanto a los estudios sobre migración interna y fecundidad en México, Brambila (1985) analizó el efecto de la migración en la fecundidad. Comparó el número promedio de hijos nacidos vivos de la población rural no migrante con el de la población que había emigrado a otros lugares rurales o urbanos. Este autor modeló los efectos de la migración en el número de hijos nacidos vivos. El modelo, además de incluir el estatus migratorio (migrante y no migrante), incluyó las variables dicotómicas origen urbano, origen metropolitano, migración antes del matrimonio y la procreación, y migración después del matrimonio pero antes de la procreación. Entre sus hallazgos más relevantes destacó que las mujeres que emigraron solteras tenían mayores probabilidades de procrear menos hijos, en comparación con las mujeres que emigraron después del matrimonio y con las mujeres no migrantes en el lugar de destino. Una explicación posible de esta tendencia refería a las expectativas mayores que pueden tener las mujeres migrantes independientes en comparación con las de mujeres agrupadas en las otras categorías. La migración previa al nacimiento del primer hijo también estuvo asociada con una fecundidad posterior más baja. Cabe señalar que también se observaron diferencias importantes 
entre los migrantes interrurales y aquellos que se dirigían a lugares urbanos y metropolitanos: por ejemplo, los migrantes rural-rural tenían probabilidades mayores de tener más hijos nacidos vivos que los que se dirigían a regiones más urbanizadas.

Por su parte, Juárez (1996), a diferencia de Brambila (1985), quien analizó el efecto de la migración interna en la fecundidad acumulada, indagó si la migración interfería con los riesgos relativos de tener un cuarto hijo. Esto porque, según la autora, la transición del tercer al cuarto hijo es el intervalo de nacimiento que marca el punto de partida para el descenso de la fecundidad (Juárez, 1986). Las estimaciones del modelo indicaron que las menores probabilidades de tener un cuarto hijo antes y después de emigrar las tenía el grupo de mujeres más educadas y de un estrato socioeconómico más elevado, lo cual confirmaba que la teoría de asimilación no estaba presente en el caso de México, por lo menos para la primera generación de mujeres migrantes. Juárez (1996) concluyó que la diferencia en los niveles de fecundidad observados entre la población migrante y la no migrante se explicaba por un proceso de selectividad en los flujos rural-urbanos. Dicho de otro modo, los migrantes que llegaban a las ciudades elegían una fecundidad más baja.

Más recientemente, Rokicki, Montana y Fink (2014) modelaron, a través de un análisis de historia de eventos, los riesgos relativos de alcanzar un embarazo (pregnacy) y también un nacimiento (live birth) en un grupo de mujeres inmigrantes en la ciudad de Accra, Ghana. La migración se operacionalizó con base en los meses acumulados de experiencia migratoria. Entre los hallazgos de esta investigación destacó que, en comparación con las mujeres no migrantes en Accra, las inmigrantes que tenían más tiempo en la ciudad presentaban mayores probabilidades de alcanzar un embarazo, pero no de alcanzar un nacimiento, lo cual se interpretó en términos de un mayor riesgo de aborto entre las mujeres inmigrantes. A diferencia de los trabajos previamente mencionados, en los cuales se discute y acredita, en la medida de lo posible, el efecto de los procesos de socialización, selectividad, ruptura o separación, adaptación y asimilación en la fecundidad de los inmigrantes internos, Rokicki et al. (2014) vinculan a la migración interna con el aborto espontáneo, un evento que sin duda interfiere con la fecundidad.

\section{Sobre la relación entre migración internacional y fecundidad}

En lo que respecta a la interrelación entre migración internacional y fecundidad, en esta sección se examinan las diferencias entre los niveles de fecundidad de la población migrante y los de la población no migrante en los países de destino. Igual que en 
la sección anterior, se discute la fecundidad de los migrantes internacionales a partir de los procesos de socialización, selectividad, ruptura o separación, adaptación y asimilación o aculturación, pero también de una hipótesis más reciente: la interrelación de eventos (Toulemon, 2004; Milewski, 2007). Asimismo, se examina la operacionalización de los conceptos y se exponen algunas de las principales limitaciones teórico-metodológicas de las investigaciones que analizan la fecundidad de los individuos que emigran a otros países.

A diferencia de los estudios sobre migración interna y fecundidad que datan de mediados de la década de los treinta del siglo pasado, la investigación sobre la relación entre migración internacional y fecundidad comenzó a finales de la década de los setenta. Massey y Mullan (1984) investigaron en Michoacán, México, los efectos de la separación temporal en la fecundidad de un grupo conformado por 351 mujeres casadas o unidas de 15 a 49 años de edad. Sin embargo, estos autores se basaron en los hallazgos teóricos de los modelos de simulación matemática desarrollados por Menken (1979) y Bongaarts y Potter (1979) para analizar el efecto reductor de la ruptura/separación en la fecundidad. En su investigación, Massey y Mullan (1984) utilizaron el método de los hijos propios para estimar las tasas específicas de fecundidad por edad. Ellos observaron que, con respecto a las tasas de fecundidad de las mujeres casadas o unidas con varones no migrantes, las tasas de fecundidad de mujeres casadas o unidas con varones migrantes eran mucho menores. Además, quienes registraron las tasas específicas de fecundidad más bajas fueron las casadas o unidas con varones migrantes documentados. Estos autores también analizaron las probabilidades de que las mujeres casadas o unidas tuvieran "hijos propios" nacidos vivos. El modelo estadístico incluyó variables sociodemográficas, el estatus migratorio de las mujeres (migrante y no migrante), el de los varones (no migrante, legal e indocumentado) y la duración del último viaje. Los resultados del modelo indicaron que las ausencias prolongadas y el estatus legal de los cónyuges o parejas reducían considerablemente la probabilidad de las mujeres de tener "hijos propios".

En Australia, Carlson (1985) describió los patrones y las tendencias en la fecundidad de los migrantes internacionales. Encontró que las mujeres que inmigraban después de formar uniones pero que todavía no tenían hijos posponían el primer embarazo. En cuanto a los intervalos entre los embarazos subsecuentes, la duración también era mayor entre las mujeres del primer grupo. Puesto que se trata de un análisis meramente descriptivo, Carlson (1985) solo especuló sobre los efectos de ruptura o separación y de adaptación. No obstante, resaltó la importancia de considerar las fases del ciclo familiar en las que ocurre la migración cuando se evalúan sus efectos en la fecundidad.

Kahn (1988) estudió el efecto de la asimilación en la fecundidad de varios grupos de inmigrantes de origen europeo, asiático y latinoamericano en Estados 
Unidos. Para identificar si adoptaban las normas de fecundidad que prevalecían en el país receptor, el autor estratificó la población de mujeres inmigrantes en dos grupos: aquellas que llegaron antes de los veinte años y las que inmigraron de veinte y más años. El autor presupuso que las mujeres que llegaron a Estados Unidos cuando tenían veinte y más años de edad adquirieron sus preferencias de fecundidad durante la infancia y juventud, a través del proceso de socialización temprana en su país de origen. En cambio, las que inmigraron más jóvenes eran mucho más receptivas a adoptar las normas reproductivas del país receptor. Kahn (1988) modeló las probabilidades de tener más hijos nacidos vivos para cada grupo. Además de controlar por los efectos del país de origen y algunas variables sociodemográficas, analizó el efecto de la selectividad en función de la escolaridad. ${ }^{4}$ Con respecto a la medición de la asimilación/aculturación, utilizó tres indicadores: 1) la experiencia migratoria acumulada en años;2) los matrimonios mixtos, y3) el conocimiento de la lengua inglesa. En cuanto a los resultados de la investigación, encontró que el nivel de fecundidad en los países de origen tenía un efecto positivo significativo en la fecundidad de los grupos de inmigrantes. Sin embargo, la intensidad del efecto disminuía entre la población inmigrante con un perfil educativo más alto que el de la población no migrante en el país de origen. Por último, las mujeres que inmigraron antes de los veinte años tenían mayores probabilidades de asimilar su fecundidad a las normas reproductivas en Estados Unidos.

También para Estados Unidos, Ford (1990) evaluó el efecto disruptivo de la migración y el de la asimilación en la fecundidad acumulada de varios grupos de mujeres inmigrantes que provenían de Europa, Canadá, el Caribe, Centro y Sudamérica. Para medir el efecto de asimilación, construyó una variable que categoriza a los inmigrantes en cuatro grupos, según el tiempo de residencia en Estados Unidos: 1) de 0 a 5 años; 2) de 6 a 10 años; 3) de 11 a 15 años, y 4) de 16 a 20 años. Los resultados del análisis mostraron que la fecundidad de los migrantes se incrementa después de inmigrar a Estados Unidos quizás porque antes de emigrar las mujeres retrasaban deliberadamente el calendario de su fecundidad. Sin embargo, una vez en el país receptor, compensaban el tiempo de reproducción perdido. Este autor también observó que a medida que se incrementa el tiempo de residencia en Estados Unidos, los niveles de fecundidad disminuyen, muy probablemente como resultado del proceso de asimilación. Conviene mencionar que el modelo de asimilación se adecuó con mucha más precisión a los inmigrantes de origen europeo escolaridad de la mujeres inmigrantes que en 1980 tenían entre 40 y 44 años con el de la población en el país de origen que en 1960 tenía entre 20 y 24 años; mientras que el segundo indicaba el nivel de escolaridad de cada grupo de inmigrantes. Posteriormente construyó variables de interacción con la tasa neta de reproducción y los indicadores de escolaridad. 
y canadiense. Según Ford (1990), la circularidad que caracterizaba a la migración caribeña, centro y sudamericana contribuía a la disrupción del comportamiento reproductivo de los individuos llegados de estas regiones.

Por su parte, Stephen y Bean (1992) investigaron si la fecundidad de un grupo de mujeres inmigrantes de origen mexicano en Estados Unidos podía explicarse en términos de las hipótesis de adaptación, asimilación y disrupción. Las medidas de la fecundidad referían al número promedio de hijos nacidos vivos y a la fecundidad reciente, por lo cual estos autores, igual que Goldstein y Goldstein (1981) y Massey y Mullan (1984), recurrieron al método de los hijos propios para estimar el número de hijos nacidos vivos menores de tres años de edad. Conviene mencionar que la muestra incluyó únicamente a mujeres casadas o unidas de entre 15 y 44 años de edad, anglosajonas y de origen mexicano. Estas últimas fueron clasificadas en dos grupos: mujeres que nacieron en México y mujeres nacidas en Estados Unidos de ascendencia mexicana. En cuanto al efecto disruptivo de la migración en la fecundidad, los resultados indicaron que este era más evidente entre las mujeres más jóvenes y en la primera generación de mujeres inmigrantes, es decir, entre aquellas que nacieron en México y después inmigraron a Estados Unidos. No obstante, a medida que aumentaba el tiempo de residencia en el país receptor la fecundidad disminuía, lo cual se interpretó como un efecto de adaptación.

La información retrospectiva de la encuesta del Proyecto sobre Migración Mexicana (MMP por sus siglas en inglés) también ha sido utilizada en los estudios sobre migración internacional y fecundidad. Lindstrom y Giorguli $(2002,2007)$ modelaron, utilizando un modelo de regresión de Poisson y un análisis de historia de eventos, los efectos de ruptura o interrupción, selectividad, adaptación y asimilación o aculturación en la fecundidad acumulada y en los riesgos relativos de alcanzar un nacimiento de un grupo de migrantes mexicanos. En ambos estudios operacionalizaron la selectividad con base en el tipo de migrante. Al respecto hay que añadir que, además del poder condicionante de la socialización, los autores supusieron que existen diferencias entre las dos categorías de migrantes en sus características no observables, como el espíritu emprendedor, la apertura a la innovación y las aspiraciones de movilidad social ascendente. Según estos autores, tales características influían sobre la fecundidad a través de las preferencias reproductivas. Por tanto, las diferencias entre la fecundidad de los migrantes temporales o de retorno y la de los permanentes podían atribuirse a un efecto de selectividad. La adaptación y la asimilación o aculturación se conceptualizaron a partir de la información sobre el tiempo de residencia en Estados Unidos y el número acumulado de viajes o cruces, respectivamente. La duración de la separación conyugal que resultó de la emigración de uno de los miembros se utilizó para medir el efecto de ruptura o interrupción en la fecundidad. Cabe señalar que en los modelos también se incluyeron variables a nivel 
de comunidad, como la prevalencia migratoria y la proporción de hombres y mujeres con experiencia migratoria. Los resultados de la investigación señalaron que la separación del núcleo conyugal tenía un efecto reductor en los riesgos relativos de alcanzar un nacimiento, pero no en la fecundidad acumulada. Para Lindstrom y Giorguli $(2002,2007)$ esta tendencia indicaba que los migrantes compensaban por el tiempo de reproducción perdido. Por otro lado, hubo diferencias significativas entre la fecundidad de los migrantes temporales o de retorno y la de los permanentes, lo cual se interpretó como un efecto de selectividad. En cuanto a los efectos de adaptación y asimilación o aculturación en la fecundidad, estos persistieron más en el grupo de migrantes radicados en Estados Unidos que en los temporales o de retorno que se encontraban en México.

Por su parte, Singley y Landale (1998) también utilizaron información retrospectiva binacional de Estados Unidos y Puerto Rico para probar la hipótesis de asimilación o aculturación en un grupo de mujeres inmigrantes de origen puertorriqueño en Nueva York. Analizaron y compararon las probabilidades de alcanzar el primer nacimiento en un grupo de mujeres que tenía experiencia migratoria previa con las de un grupo de mujeres no migrantes en Puerto Rico. Además, compararon las probabilidades de alcanzar el primer nacimiento de un grupo mujeres inmigrantes de origen puertorriqueño con las de población no migrante en Nueva York. El análisis incluyó el tiempo de residencia en Estados Unidos como una medida aproximada a los procesos de adaptación y asimilación o aculturación. Entre los hallazgos de esta investigación destacó que, en comparación con las mujeres no migrantes en Puerto Rico, las que tenían más tiempo en Estados Unidos tenían menos probabilidades de alcanzar el primer nacimiento, lo cual se interpretó en el marco de la hipótesis de asimilación o aculturación.

Ng y Nault (1997) analizaron el efecto disruptivo de la migración en la fecundidad de las mujeres inmigrantes de 15 a 49 años de edad en Canadá con el uso de datos censales de 1991. Con respecto al tiempo de residencia en Canadá, las mujeres inmigrantes fueron agrupadas en tres categorías: 1) migración reciente (de cero a cinco años); 2) migración de mediano plazo (de seis a diez años), y 3 ) migración de largo plazo (más de diez años). Mediante la comparación de los resultados del método de los hijos propios, los autores hicieron notar que las tasas de fecundidad general diferían entre cada una de las categorías de mujeres migrantes, según el tiempo de residencia en Canadá. Sin embargo, también observaron que existían diferencias importantes entre los resultados obtenidos a partir del método de los hijos propios y de su variante. Argumentaron que el método de los hijos propios capturaba el comportamiento de la fecundidad antes de la emigración, lo cual sobrestimaba el efecto disruptivo de la migración en la fecundidad. Por tanto, su variante era mucho mejor indicador del efecto supresor de la migración en la fecundidad. Por lo que toca 
al efecto disruptivo de la migración en la fecundidad, los autores concluyeron que si bien el análisis descriptivo de la información apuntaba hacia una posible reducción de la fecundidad en el tiempo que sigue a la emigración, la evidencia no era suficiente. En cambio, la reducción en los niveles de fecundidad de las mujeres inmigrantes conforme se incrementaba el tiempo de residencia en Canadá sugería que las mujeres asimilaban y adoptaban las normas reproductivas del país receptor.

Más recientemente, el continuo incremento de la inmigración en Europa ha despertado interés por conocer el impacto del proceso de asimilación o aculturación en la fecundidad de los inmigrantes. Para Alemania, Mayer y Riphahn (2000) utilizaron información de la Encuesta Panel Socioeconómica Alemana (GSOEP, por sus siglas en inglés) con el objetivo de identificar los efectos de asimilación o aculturación en la fecundidad acumulada de las mujeres inmigrantes de origen turco, griego, italiano, español y eslavo. En el modelo, además de controlar por los efectos de variables demográficas y socioeconómicas básicas, los autores incluyeron variables que daban cuenta del número de años fértiles que las mujeres inmigrantes habían pasado en Alemania. Según ellos, estas variables eran buenos indicadores para determinar si los niveles de fecundidad de los distintos grupos de mujeres inmigrantes podían explicarse en términos de la hipótesis de asimilación o aculturación. Los hallazgos de la investigación indicaron que al llegar a Alemania, las mujeres inmigrantes poseían niveles de fecundidad superiores a los de las mujeres alemanas. Sin embargo, a medida que se incrementaba el número de años fértiles que las mujeres inmigrantes habían pasado en Alemania, sus niveles de fecundidad se reducían, con lo cual se comprobaba el efecto de asimilación o aculturación en la fecundidad de las mujeres inmigrantes de origen turco, italiano, español y eslavo, pero no en la fecundidad de aquellas de origen griego.

Milewski (2007) también utilizó datos de la GSOEP para analizar si los procesos de ruptura o interrupción y de adaptación interferían con las probabilidades de alcanzar el primer nacimiento de las mujeres inmigrantes de origen turco, eslavo, griego, italiano y español. Para comprobar si la asimilación o aculturación se asociaban a la fecundidad de las mujeres inmigrantes, la autora construyó una variable categórica que aludía a la generación del migrante, es decir, si se trataban de migrantes de primera o de segunda generación. Además, el modelo incluyó una variable que capturaba el tiempo de residencia en Alemania. Los resultados indicaron que las probabilidades de alcanzar el primer nacimiento se incrementaban poco después de inmigrar en Alemania, sobre todo entre la primera generación de inmigrantes. No obstante, Milewski (2007) consideró que este resultado no probaba la hipótesis de ruptura o separación, sino que debía ser interpretado en términos de una hipótesis alternativa que resaltara la interconexión de acontecimientos demográficos y sociales, tales como la migración, la reunificación familiar y la fecundidad. 
Para Suecia, Andersson (2004) utilizó información censal para comparar las probabilidades que tenían las mujeres inmigrantes de alcanzar el primero, segundoy tercer nacimiento con las de las mujeres suecas. Las inmigrantes de origen turco, norteafricano y árabe con menos de cuatro años de haber inmigrado a Suecia tenían mayores probabilidades de alcanzar el primer nacimiento que las mujeres suecas. No obstante, a medida que se incrementaba el tiempo de estancia en el país receptor se reducía la diferencia en las probabilidades de alcanzar el primer nacimiento. Lo mismo ocurría con los nacimientos de orden mayor. Andersson (2004) interpretó estos resultados en términos de los procesos de asimilación o aculturación.

Con datos del censo griego de 2001, Bagavos, Tsimbos y Verropoulou (2008), además de describir las tendencias de fecundidad de las mujeres inmigrantes de origen albanés y búlgaro con respecto a las de las mujeres griegas, compararon las características demográficas y socioeconómicas de los inmigrantes albaneses y búlgaros con las de la población no migrante en sus países de origen. Aunque los resultados del análisis descriptivo advirtieron la presencia de un posible efecto de selectividad y otro de asimilación o aculturación, no realizaron un análisis estadístico inferencial que comprobara si estos dos procesos en verdad explicaban los niveles de fecundidad de los inmigrantes de origen albanés y búlgaro en Grecia.

Igual que Massey y Mullan (1984) y Lindstrom y Giorguli (2002, 2007), quienes analizaron los efectos de la migración internacional en la fecundidad de los migrantes en el país de origen, Lerch (2009) evaluó para Albania el impacto de la emigración internacional en la fecundidad. A partir de información de los censos de 1989 y 2001 y de la Encuesta Albanesa sobre los Niveles de Vida de 2002, este autor modeló los riesgos relativos de alcanzar el primer nacimiento y nacimientos de orden mayor de las mujeres casadas de entre 15 y 49 años de edad. Conviene mencionar que el efecto de la migración se midió a partir del estatus migratorio de sus cónyuges, es decir, si el varón era migrante o no migrante. Con respecto a los resultados del modelo, Lerch (2009) encontró que para las mujeres casadas con varones con experiencia migratoria internacional, a pesar de haber comenzado su vida reproductiva a edad más temprana, los riesgos de alcanzar nacimientos de primer orden y de orden mayor eran mucho menores que los de las mujeres casadas con varones no migrantes. Según el autor estos resultados se podían explicar a partir de la hipótesis de ruptura o separación. Sin embargo, reconoció que en los países de destino, los y las migrantes internacionales se exponen a normas reproductivas que favorecen descendencias de menor tamaño, las cuales pueden internalizarse mediante los procesos de asimilación o aculturación. Por tanto, cuando los migrantes retornan a sus países de origen con nuevos valores en torno a la reproducción, esto puede contribuir a una reducción en sus niveles de fecundidad. 
Tomando en cuenta lo anterior, White y Buckley (2011) investigaron si en Turquía la experiencia migratoria internacional representaba un factor asociado a la fecundidad. Construyeron una variable que capturaba si las mujeres de 15 a 49 años de edad habían estado expuestas a la migración internacional. Constituyeron cuatro categorías: 1) mujeres en hogares no migrantes;2) mujeres con experiencia migratoria; 3) cónyuge con experiencia migratoria, y 4) otros miembros del hogar con experiencia migratoria. Cabe señalar que en el modelo de regresión logística la variable dependiente era el número de hijos nacidos vivos. Entre los hallazgos de esta investigación destacó que las mujeres con experiencia migratoria y las que tenían esposos emigrantes procreaban menos hijos que las pertenecientes a núcleos conyugales no migrantes. Estos autores argumentaron que tales tendencias podían estar vinculadas, primero, al proceso de selectividad migratoria, puesto que las mujeres que habían emigrado tenían más altos niveles de escolaridad, residían en áreas urbanas y reportaban actitudes que no favorecían los sistemas patriarcales y los matrimonios concertados; y segundo, al efecto de la separación temporal del núcleo conyugal, el cual reduce la frecuencia de las relaciones sexuales y, por tanto, el riesgo de embarazos.

Para España, Castro Martin y Roseo-Bixby (2011) analizaron la fecundidad de un grupo de mujeres inmigrantes del norte de África. Los hallazgos de su investigación mostraron menores niveles de fecundidad entre las mujeres que inmigraron estando casadas, que tenían uno o más hijos nacidos vivos y que reportaron haber inmigrado por razones laborales. Por el contrario, las mujeres casadas con o sin hijos que inmigraron por motivos de reunificación familiar registraron altos niveles de fecundidad poco después de haber inmigrado. Para Italia, Mussino y Strozza (2012) llegaron a conclusiones similares argumentando que las diferencias en las tendencias de la fecundidad de las mujeres inmigrantes podían explicarse con base en los motivos de la migración. A diferencia del resto de las investigaciones, en los trabajos de Castro Martin y Roseo-Bixby (2011) y de Mussino y Strozza (2012) no se ponen a discusión las hipótesis que explican la fecundidad de los migrantes.

La aparición de encuestas longitudinales ha permitido complejizar la investigación sobre la relación entre migración y fecundidad. Sin embargo, la información transversal se sigue utilizando en algunos casos. Por ejemplo, Adserá y Ferrer (2016) analizaron la fecundidad de un grupo de mujeres inmigrantes casadas de entre $18 \mathrm{y}$ 45 años de edad en Canadá utilizando datos censales. Ellas fueron reagrupadas en dos categorías: 1) mujeres que tenían hijos antes de inmigrar, y 2) mujeres que no tenían hijos antes de inmigrar. Para estas dos categorías, las autoras modelaron los riesgos relativos de alcanzar un nacimiento durante los primeros dos años de residencia en el país de destino. Los resultados del modelo indicaron que las probabilidades de alcanzar el primer nacimiento se incrementaban poco después de 
inmigrar en Canadá, sobre todo entre las mujeres que no tenían hijos antes de inmigrar. Las autoras consideraron que este resultado podía ser interpretado en términos de la hipótesis de la interrelación de eventos (Toulemon, 2004; Milewski, 2007). Sin embargo, identificaron algunas diferencias según la nacionalidad, lo cual, argumentaron, podría tener que ver con los procesos de socialización en los países de origen.

\section{Reflexiones de carácter teórico-metodológico respecto a la evolución de la investigación sobre migración y fecundidad}

En este trabajo se hizo una revisión de las transformaciones que experimentó la investigación sobre migración y fecundidad durante el periodo de 1970 a 2016. Particularmente interesantes resultaron las diferencias de carácter teórico e histórico entre los estudios que analizan los efectos de la migración interna en la fecundidad y los que la asocian a la migración internacional. Asimismo, la investigación sobre la relación entre migración y fecundidad demuestra que los procesos migratorios son un componente fundamental para la reproducción demográfica de cualquier población (Canales, 2015). ${ }^{5}$ La migración interna e internacional modifica la estructura etaria y la composición por sexo tanto en los lugares de origen como en los de destino, y además generan contextos socioeconómicos particulares que pueden beneficiar a ciertos grupos poblacionales y perjudicar a otros. Por tanto, Canales (2015) sugiere referirse a la migración como un proceso que contribuye a la configuración de un régimen o sistema global de reproducción demográfica que involucra lo que sucede tanto en los lugares de origen como en los de destino.

Con base en lo anterior, se puede argumentar que el interés por estudiar la dinámica entre la fecundidad y la migración interna, específicamente en los países considerados como subdesarrollados, surgió a partir de la preocupación que generaba la terciarización de la economía rural, la expulsión del excedente poblacional hacia las ciudades y la urbanización, todo esto a consecuencia del crecimiento demográfico acelerado y del proceso de modernización. Con respecto a los factores que motivan los estudios sobre los nexos entre la migración internacional y la fecundidad, destacan los siguientes: 1) la contribución demográfica de la población inmigrante a las transformaciones en la composición etaria y étnica de los países de imbricación de la migración internacional con otros fenómenos demográficos, como el envejecimiento poblacional, el bono demográfico y la fecundidad, Canales (2015) se refiere a los casos de Estados Unidos y España. 
destino, a través de su llegada y su fecundidad; 2) las consecuencias laborales y económicas del cambio composicional en la estructura por edad y sexo tanto en los países de origen como en los de destino; 3 ) la importancia de la fecundidad de la población inmigrante para contrarrestar el descenso de la natalidad en los países receptores; 4) los costos potenciales para el fisco y los programas de salud pública y de asistencia social, y 5) los retos y las dificultades de la integración de los inmigrantes a la sociedad de destino.

Con respecto a la operacionalización de las hipótesis que explican la fecundidad de la población migrante, la hipótesis de disrupción o separación se conceptualiza a partir de la información sobre la duración de la separación del núcleo conyugal (véase Lindstrom \& Giorguli, 2002, 2007) o bien se mide en función del efecto que tienen otras variables socioeconómicas sobre la fecundidad, como la incorporación inmediata de las mujeres inmigrantes al mercado laboral en el lugar de destino (véase Singley \& Landale, 1998). En cuanto a la selectividad migratoria, se trata del concepto que más variantes presenta. En los estudios sobre migración interna y fecundidad, los efectos de la selectividad se controlan al considerar el lugar de procedencia de los migrantes, es decir, ya sea rural o urbana. Esta conceptualización se fundamenta en la hipótesis de socialización, la cual sostiene que las preferencias de fecundidad se interiorizan durante la infancia y la juventud (Hervitz, 1985; Juárez, 1996; Castro Martín \& Roseo-Bixby, 2011). Cabe señalar que el tipo de localidad de procedencia de los migrantes es fundamental para explicar su fecundidad, ya que se vincula al comportamiento reproductivo futuro (Juárez, 1996). En los estudios sobre migración internacional los procedimientos para la medición del efecto de selectividad en la fecundidad han sido mucho más creativos. Por ejemplo, mediante la interacción de dos variables explicativas vinculadas a la fecundidad y la escolaridad (Kahn, 1998), la utilización de métodos alternativos para la recolección de datos de fecundidad ( $\mathrm{Ng} \&$ Nault, 1997), la tasa global de fecundidad en el país de origen (Ford, 1990) e incluso la situación conyugal de los inmigrantes (Singley \& Landale, 1998).

Conviene mencionar que, a diferencia de los trabajos sobre migración interna y fecundidad, en aquellos sobre la relación entre la migración internacional y la fecundidad no se discute - al menos no de manera explícita- el poder condicionante de la socialización temprana sobre las preferencias reproductivas. Sin embargo, Lindstrom y Giorguli $(2002,2007)$ retomaron este argumento para fundamentar la operacionalización del concepto de selectividad, la cual incluyó dos categorías: migrante temporal o de retorno (temporary/return migrant) y migrante permanente (settled migrant). Al respecto hay que añadir que, además del poder condicionante de la socialización, estos autores supusieron que existían diferencias entre las dos categorías de migrante y las características no observables, tales como el espíritu 
emprendedor, la apertura a la innovación y las aspiraciones de movilidad social ascendente, las cuales influían sobre la fecundidad a través de las preferencias de fecundidad. Por tanto, las diferencias entre la fecundidad de los migrantes temporales o de retorno y la de los migrantes permanentes podían atribuirse a un efecto de selectividad.

Los indicadores tanto de adaptación como de asimilación o aculturación por lo regular se construyen con base en los meses o años acumulados de experiencia migratoria, o bien a través variables categóricas que aluden a la generación del migrante. Por lo regular, los efectos de asimilación/aculturación en la fecundidad son mayores en la segunda y tercera generación de inmigrantes, sin importar su nacionalidad (Milewski, 2007). Dado que esta revisión de la literatura refiere solamente a inmigrantes de primera generación, no se revisaron trabajos que profundizan en cómo es que el proceso de asimilación/aculturación interfiere con la fecundidad de los hijos o nietos de inmigrantes nacidos en el lugar de destino. Sin embargo, dada la importancia de la contribución demográfica de la población inmigrante a las transformaciones en la composición étnica de los países de destino, vale mencionar que un número importante de investigaciones se centra en la fecundidad de las mujeres migrantes de segunda y tercera generación para dilucidar los efectos de los procesos de asimilación o aculturación.

Buena parte de las investigaciones en torno a la fecundidad de la población migrante de segunda y tercera generación refiere a las mujeres nacidas en Estados Unidos de origen hispano y mexicano, probablemente porque se estima que esta población crece más rápido que el resto de la población en aquel país debido a una fecundidad más elevada (Parrado, 2011, 2015). Kahn (1994), por ejemplo, analizó los efectos de asimilación o aculturación en la fecundidad de un grupo de mujeres migrantes de origen mexicano, latinoamericano, indochino, asiático y europeo. Mediante la utilización de información censal de la Current Population Survey (CPS), el autor encontró que los niveles de fecundidad de las mujeres de origen mexicano se encontraban por arriba de los de las mujeres inmigrantes de origen asiático y europeo, así como de los de la población no migrante. Más recientemente, Parrado y Morgan (2008) demostraron a través un análisis comparativo de cohorteperiodo que la fecundidad de las mujeres de origen hispano y mexicano se asemeja a la de las mujeres anglosajonas. Los autores vincularon los hallazgos a mayores aspiraciones de movilidad social ascendente, pero también a procesos de asimilación/aculturación. Posteriormente, Parrado (2011) estudió los problemas de medición y sesgos para la estimación de la fecundidad de las mujeres migrantes de primera, segunda y tercera generación a partir de información transversal, la cual no refleja adecuadamente los cambios intergeneracionales e incrementa la probabilidad de cometer errores de sobreestimación. Esto, según el autor, puede distorsionar 
las tendencias y los patrones de la fecundidad de la población inmigrante y dar lugar a políticas migratorias que perjudiquen a grupos específicos de migrantes.

Es importante mencionar que, con excepción de la hipótesis de disrupción o separación, el resto refiere a las preferencias reproductivas, es decir, al tamaño deseado de la descendencia, al tiempo ideal de espera y al deseo de más hijos como un factor que influye en la fecundidad de los migrantes. Sin embargo, pocos trabajos investigan la relación entre estos procesos y las preferencias de fecundidad (Kahn, 1994; Zerden, Stuart, Verbiest, DeRosset \& Tang, 2013; Regules, 2014). Probablemente la ausencia de investigaciones cuantitativas en torno a la relación entre las preferencias de fecundidad y la migración internacional se debe a la omisión de información sobre las preferencias de fecundidad en las encuestas sobre migración, o bien a la falta de una muestra representativa de la población migrante en la mayoría de las encuestas que recaban información completa sobre el comportamiento reproductivo. ${ }^{6}$

Con respecto a las fuentes de datos y las herramientas estadísticas y analíticas, sorprende su gran diversidad. Las primeras investigaciones sobre la relación entre migración y fecundidad utilizaron datos de corte transversal para presentar estadísticas descriptivas o análisis bivariados, mientras que en las más recientes predomina el uso de encuestas longitudinales o de panel. La evolución de las bases de datos, así como la inclusión en ellas de información sobre las trayectorias migratorias y reproductivas, ha permitido incorporar a las investigaciones nuevas técnicas de análisis estadístico de datos, como el análisis de riesgos relativos, pero también vincular la migración con otros eventos del ciclo de vida, por ejemplo el matrimonio y los nacimientos de orden mayor. Además, los volúmenes y la mejora en la calidad de la información captada a través de diversas encuestas han permitido desagregar las tendencias de la fecundidad (Kulu \& González Ferrer, 2014) y refinar, a través de nuevas técnicas estadísticas, la construcción de indicadores de socialización, adaptación, asimilación/aculturación y controlar de manera más precisa por los efectos de selectividad y ruptura/separación. No obstante, en muchos de los trabajos y demográfica que permite no solo la reconstrucción de la trayectoria migratoria y de la historia de nacimientos sino también el análisis de la relación entre estos dos eventos. No obstante, ninguna recolecta información sobre las preferencias de fecundidad. Por el contrario, la Encuesta Nacional de la Dinámica Demográfica (Enadid), además de recabar información sobre migración, la recolecta sobre las preferencias de fecundidad, pero solo de las mujeres. La Enadid sería útil si en esta investigación se supusiera que únicamente la migración de las mujeres interfiere con sus preferencias de fecundidad. Sin embargo, en esta investigación se analizan las preferencias de fecundidad tanto de las mujeres como de sus cónyuges; por tanto, se utilizó la Encuesta Nacional sobre los Niveles de Vida de los Hogares de 2002 y 2005 (ENNViH), la cual cuenta con información no únicamente sobre las trayectorias migratorias de varones y mujeres, sino también sobre sus preferencias de fecundidad. 
revisados se reconoce la dificultad para distinguir si las tendencias de la fecundidad en la población migrante resultan del proceso de selectividad migratoria, que a su vez refiere a mayores aspiraciones de movilidad social ascendente entre la población migrante, o bien al proceso de adaptación.

Finalmente, en el caso mexicano las encuestas han tendido a medir la migración desde una perspectiva estática y no con un enfoque dinámico. Por ejemplo, los censos de población y la Enadid levantan información solo de los migrantes encuestados, excluyendo así a la población migrante que estaba residiendo en otro municipio u otro país al momento de la encuesta. Sin embargo, el MMP, la Eder y la ENNViH recaban información migratoria, socioeconómica y demográfica que permite no solo la reconstrucción de la trayectoria migratoria y de la historia de nacimientos sino también el análisis de la relación entre estos dos eventos desde una perspectiva longitudinal.

\section{Consideraciones finales}

Si bien en los trabajos más recientes se han propuesto nuevas hipótesis que enfatizan la interconexión de acontecimientos demográficos y sociales como la migración, la reunificación y la formación familiar, las perspectivas analíticas continúan favoreciendo trabajos que vinculan los niveles y las tendencias de fecundidad de las personas migrantes a los procesos de socialización, selectividad, ruptura/separación, adaptación y asimilación o aculturación. En mi opinión, valdría la pena retomar algunos argumentos de la hipótesis de la interrelación de eventos, pero también incorporar en el análisis los factores que incentivan la inmigración (laboral, reunificación familiar). Asimismo, la investigación sobre la relación entre migración y fecundidad, específicamente en el caso de la migración internacional, debe considerar las posibles consecuencias de los nuevos arreglos y dinámicas familiares que surgen en contextos de alta inmigración, por ejemplo los matrimonios mixtos y las tasas de divorcio, sobre la fecundidad.

La migración es un proceso que añade complejidad a las relaciones familiares. Sin embargo, la mayoría de las hipótesis que explican el comportamiento reproductivo de la población migrante no consideran las consecuencias sociales y psicoemocionales de la migración, las cuales muy probablemente pueden incidir en la fecundidad. Las consecuencias de las ausencias cada vez más prolongadas de los varones por ejemplo, la incertidumbre con respecto a la fidelidad, el ablandamiento de los lazos afectivos y la adquisición de mayores responsabilidades por parte de las mujeres, podrían interferir con las decisiones reproductivas futuras. De igual manera, habría que incorporar, o al menos considerar, en la investigación cuáles son 
las consecuencias, los costos afectivos y emocionales de la separación conyugal/familiar, sobre la fecundidad. Por otro lado, en los lugares de destino, habría que preguntarse si la dificultad para acceder a los servicios de salud, las barreras lingüísticas, las restricciones impuestas por los horarios laborales (lo cual limita la articulación entre el trabajo y el cuidado de los hijos) y las condiciones de estancia migratoria, de segregación laboral y residencial son factores que interfieren con la fecundidad de la población migrante.

Otro aspecto que se debe considerar son los nuevos escenarios de la migración en México y el mundo (desplazados internos forzados, refugiados, migrantes de retorno, migrantes en tránsito), lo cual obliga a replantearse la pertinencia de los marcos analíticos tradicionales y su capacidad de análisis e interpretación de la fecundidad de las poblaciones migrantes bajo este nuevo contexto.

En cuanto a la investigación sobre la interrelación entre la migración interna y la fecundidad en México, sorprende la escasez de trabajos, sobre todo con respecto al volumen de la producción académica desarrollada en años recientes en los países europeos. Dado el incremento de emigrantes de procedencia urbana y que el campo continúa expulsando fuerza de trabajo a las ciudades, valdría la pena retomar la investigación sobre la relación entre migración interna y fecundidad.

Si bien esta revisión de la literatura se centró en la fecundidad marital tanto de los migrantes internos como de los internacionales, vale mencionar la existencia de trabajos que vinculan el embarazo adolescente a la migración (Palma Cabrera, 2016). Esto es importante porque, independientemente del tipo de migración, los procesos migratorios podrían interferir con otras dimensiones del comportamiento reproductivo, como el embarazo adolescente, el aborto espontáneo o inducido, los nacimientos prematuros y el uso de métodos anticonceptivos.

Otro aspecto importante, en futuras investigaciones, sería la incorporación en el análisis de la fecundidad de las experiencias premigratorias en el lugar de origen, la experiencia de la migración y la experiencia posmigratoria (véase Bhugra, 2003). Con respecto a los métodos, la revisión de la literatura dejó en claro la preferencia por métodos cuantitativos. Sin embargo, es fundamental la utilización de aproximaciones metodológicas cualitativas o mixtas, a fin de cuestionar los supuestos que subyacen a la construcción de indicadores; dar cuenta de las características no observables, como el espíritu emprendedor, la apertura a la innovación y las aspiraciones de movilidad social ascendente; y profundizar en algunos de los aspectos mencionados en los párrafos anteriores. 


\section{Referencias}

Adserá, A. \& Ferrer, A. (2016). The fertility of married immigrant women to Canada. International Migration Review, 50, 475-505.

Amaro, H. (1988). Women in the Mexican-American community: religion, culture, and reproductive attitudes and experiences. Journal of Community Psychology, 16, 6-20.

Andersson, G. (2004). Childbearing after migration: fertility patterns of foreign-born women in Sweden. International Migration Review, 38, 747-774.

Bach, R. L. (1981). Migration and fertility in Malaysia: a tale of two hypotheses. International Migration Review, 15, 502-521.

Bankole, A. \& Singh, S. (1998). La decisión de la pareja en cuestiones de fecundidad y anticoncepción en los países en desarrollo: escuchar la opinión del hombre. Perspectivas Internacionales en Planificación Familiar, núm. especial, 18-37.

Bankole, A. \& Westoff, C. F. (1998). Childbearing attitudes and intentions. DHS Comparative Studies No. 17, Calverton, Macro International Inc.

Bhugra, D. (2003). Migration and depression. Acta Psychiatrica Scandinavica, 108, 77-82.

Bledsoe, C.H. (20049. Reproduction at the margins: migration and legitimacy in the new Europe. Demographic Research, special collection 3, 87-116.

Bongaarts, J. (1992). Do reproductive intentions matter? International Family Planning Perspectives, 18, 102-108.

Bongaarts, J. \& Potter, R. G. (1979). Fertility effect of seasonal migration and seasonal variation in fecundability: test of a useful approximation under more general conditions. Demography, 16, 475-479.

Brambila Paz, C. (1985). Migración y formación familiar en México. México: El Colegio de México.

Canales, A. I. (2015). El papel de la migración en el sistema global de reproducción demográfica. Notas de Población, 100, 91-123.

Carlson, E. D. (1985). The impact of international migration upon the timing of marriage and childbearing. Demography, 22, 61-72.

Castro Martín, T. \& Roseo-Bixby, L. (2011). Maternidades y fronteras. La fecundidad de las mujeres inmigrantes en España. Revista Internacional de Sociología, 1, 105-137.

Chattopadhyay, A., White, M. J. \& Depbuur, C. (2006). Migrant fertility in Ghana: selection versus adaptation and disruption as causal mechanisms. Population Studies, 60, 189203.

Dorn, H. F. \& Lorimer, F. (1936). Migration, reproduction, and population adjustment. The Annals of the American Academy of Political and Social Science, 188, 280-289.

Farber, S. C. \& Lee, B.S. (1984). Fertility adaptation of rural-to-urban migrant women: a method of estimation applied to Korean women. Demography, 21, 339-345.

Ford, K. (1990). Duration of residence in the United States and the fertility of U.S. immigrants. International Migration Review, 24, 34-68. 
Frank, R. \& Heuveline, P. (2005). A crossover in Mexican and Mexican-American fertility rates: evidence and explanations for an emerging paradox. Demographic Research, 12, 77-104.

Goldstein, S. (1973). Interrelations between migration and fertility in Thailand. Demography, 10, 225-241.

Goldstein, S. \& Goldstein, A. (1981). The impact of migration on fertility: an 'own children' analysis for Thailand. Population Studies, 35, 265-284.

Goldstein, S. \& Goldstein, A. (1983). Migration and fertility in peninsular Malaysia: an analysis using life history data. The Agency for International Development.

Gyimah, S. O. (2006). Migration and fertility behavior in Sub-Saharan Africa: the case of Ghana. Journal of Comparative Family Studies, 22, 235-252.

Hervitz, H. M. (1985). Selectivity, adaptation, or disruption? A comparison of alternative on the effects of migration on fertility: the case of Brazil. International Migration Review, 19, 293-317.

Jensen, E. \& Ahlburg, D. A. (2004). Why does migration decrease fertility? Evidence from the Philippines. Population Studies, 58, 219-231.

Juárez, F. (1996). La formación de la familia y la movilidad a las áreas metropolitanas en México: un nuevo enfoque de la interacción entre eventos demográficos. En Juárez, F., Quilodrán, J. \& Zavala de Cosío, M. E. (eds.), Nuevas pautas reproductivas en México (pp. 147-198). México: El Colegio de México.

Kahn, J. R. (1988). Immigrant selectivity and fertility adaptation in the United States. Social Forces, 67, 108-128.

Kahn, J. R. (1994). Immigrant and native fertility during the 1980s: adaptation and expectations for the future. International Migration Review, 28, 501-519.

Kiser, C. V. (1938). Birth rates among rural migrants in cities. The Milbank Memorial Fund Quarterly, 16, 369-381.

Kulu, H. (2003). Migration and fertility: competing hypotheses re-examined. Max-PlanckInstitute for Demographic Research (MPIDR) Working Paper WP 2003-035.

Kulu, H. (2006). Fertility of internal migrants: comparison between Austria and Poland. Population, Space and Place, 12, 147-170.

Kulu, H. \& González Ferrer, A. (2014). Family dynamics among immigrants and their descendants in Europe: current research and opportunities. European Journal of Population, 30, 411-435.

Lee, B. S. (1992). The influence of rural-urban migration on migrant's fertility behavior in Cameroon. International Migration Review, 26, 1416-1447.

Lee, B. S. \& Farber, S. C. (1985). The influence of rapid rural-urban migration on Korean national fertility levels. Journal of Development Economics, 17, 47-71. 
Lee, B. S. \& Pol, L. G. (1993). The influence of rural-urban migration on migrant's fertility in Korea, Mexico and Cameroon. Population Research and Policy Review, 12, 3-26.

Lerch, M. (2009). The impact of migration on fertility in post-communist Albania. Southeast European and Black Sea Studies, 9, 519-537.

Lindstrom, D. P. y Giorguli Saucedo, S. (2002). The short- and long-term effects of U.S. migration experience on Mexican women's fertility. Social Forces, 80, 1341-1368.

Lindstrom, D. P. y Giorguli Saucedo, S. (2007). The interrrelationship between fertility, family maintenance, and Mexico-U.S. migration. Demographic Research, 17, 821-858.

Macisco, J. J., Bouvier, L. F. \& Renzi, M. J. (1969). Migration status, education and fertility in Puerto Rico, 1960. The Milbank Memorial Quarterly, 47, 167-186.

Macisco, J. J.,Bouvier, L. F. \& y Weller, H. R. (1970). The effect of labor force participation on the relation between migration status and fertility in San Juan, Puerto Rico. The Milbank Memorial Quarterly, 48, 51-70.

Massey, D. S. \& Mullan, B. P. (1984). A demonstration of the effect of seasonal migration on fertility. Demography, 21, 501-517.

Mayer, J. \& Riphahn, R. T. (2000). Fertility assimilation of immigrants: evidence from count data models. Journal of Population Economics, 13, 241-261.

Menken, J. (1979). Seasonal migration and seasonal variation in fecundability: effects on birth rates and birth intervals. Demography, 16, 697-717.

Milewski, N. (2007). First child of immigrant workers and their descendants in West Germany: interrelation of events, disruption, or adaptation? Demographic Research, 17, 859-896.

Milewski, N. (2011). Transitions to a first birth among Turkish second-generation migrants in Western Europe. Advances in Life Course Research, 16, 178-189.

Monnier, A. (1989). Fertility intentions and actual behaviour. A longitudinal study: 1974, 1976, 1979. Population: An English Selection, 44 (1), 237-259.

Mussino, E. \& Strozza, S. (2012). The fertility of immigrants after arrival: the Italian case. Demographic Research, 26, 99-130.

Nair, N. K. \& Chow, L. P. (1980). Fertility intentions and behavior: some findings from Taiwan. Studies in Family Planning, 11, 255-263.

Ng, E. \& Nault, F. (1997). Fertility among recent immigrant women to Canada, 1991: an examination of the disruption hypothesis. International Migration, 35, 559-570.

Palma Cabrera, Y. (2016). El embarazo adolescente en un contexto de alta inmigración. Notas de Población, 103, 9-27.

Parrado, E. A. (2011). How high is Hispanic/Mexican fertility in the United States? Immigration and tempo considerations. Demography, 48, 1059-1080.

Parrado, E. A. (2015). Migration and fertility. International Encyclopedia of the Social and Behavioral Science, 15, 397-406. 
Parrado, E. A. \& Morgan, P. (2008). Intergenerational fertility among Hispanic women: new evidence of immigrant assimilation. Demography, 45, 651-671.

Perlmann, J. \& Waldinger, R. (1997). Second generation decline? Children of immigrants, past and present - A reconsideration. The International Migration Review, 3, 893-922.

Regules García, R. (2014). Sí quiero ... y no puedo ... Migración y el imaginario reproductivo. Tesis doctoral, El Colegio de México, Centro de Estudios Demográficos, Urbanos y Ambientales. Ciudad de México.

Rodriguez, G. \& Hobcraft, J.N. Illustrative analysis: life table analysis of birth intervals in Colombia. World Fertility Survey Scientific Report, No. 16.

Rokicki, S, Montana, L. \& Fink, G. (2014). Impact of migration on fertility and abortion: evidence from the household and welfare study of Accra. Demography, 51, 2229-2254.

Roy, T. K., Sinha, R. K., Koenig, M., Mohanty, S. K. \& Patel, S. K. (2008). Consistency and predictive ability of fertility preference indicators: longitudinal evidence from rural India. International Family Planning Perspectives, 34, 138-145.

Silva De, W. I. (1991). Consistency between reproductive preferences and behavior: the Sri Lankan experience. Studies in Family Planning, 22, 188-197.

Singley, S. G. \& Landale, N. S. (1998). Incorporating origin and process in migration-fertility frameworks: the case of Puerto Rican women. Social Forces, 76, 1437-1464.

Stephen, E. H. \& Bean, F. D. (1992). Assimilation, disruption and the fertility of Mexicanorigin women in the United States. International Migration Review, 26, 67-88.

Toulemon, L. (2004). La fecondité des immigrées: nouvelles données, nouvelle aproche. Population et Sociétés, 400.

Toulemon, L. \& Mazuy, M. (2004). Comment prendre en comprte l'âge à l'arrivée et la durée de séjour en France dans la mesure de la fécondité des immigrants?. Documents de Travail 120. INED.

Weller, R. H. y Macisco, J. J. Jr. (1971). Fecundidad, migración y aspiraciones de movilidad social en los países en desarrollo: sugerencias para investigación. Demografía Económica, 1, 56-76.

White, K. \& Buckley, C. J. (2011). Exposure to international migration and its effect on childbearing in Turkey. International Migration Review, 45, 123-147.

White, M. J., Moreno, L. \& Guo, S. (1995). The interrelation of fertility and geographic mobility in Peru: a hazards model analysis. International Migration Review, 29, 492-514.

Zerden, M. L., Stuart, G. S., Verbiest, S., DeRosset, L. \& Tang, J. (2013). Family planning intentions: a qualitative exploration of postpartum women of Mexican descent in North Carolina. Contraception, 88, 624-628. 